\title{
A PERCEPÇÃO DE PESSOAS COM DEFICIÊNCIA INTELECTUAL SOBRE A SEXUALIDADE
}

\author{
LA PERCEPCIÓN DE LAS PERSONAS CON DEFICIENCIA INTELECTUAL ACERCA \\ DE LA SEXUALIDADE
}

\author{
THE PERCEPTION OF PERSONS WITH INTELLECTUAL DISABILITIES ON \\ SEXUALITY
}

\author{
Pâmela Coimbra Argenton PUGA ${ }^{1}$ \\ Andrea RUZZI-PEREIRA ${ }^{2}$
}

\begin{abstract}
RESUMO: A sexualidade de pessoas com deficiência intelectual ainda é um tabu, mas é entendida pela terapia ocupacional como etapa fundamental para a vida. Objetivo: descrever a percepção de pessoas com deficiência intelectual sobre a sexualidade. Método: estudo exploratório descritivo, de natureza qualitativa, realizado com oito alunos de uma instituição para pessoas com deficiências, com idade entre 13 e 42 anos. Utilizou-se uma entrevista semiestruturada para investigar a percepção sobre a sexualidade e coletar dados sociodemográficos; para a avaliação dos dados utilizou-se a análise de conteúdo temáticocategorial. Resultados: a análise de conteúdo possibilitou estabelecer duas categorias temáticas: experiências em relacionamento afetivo; e conhecimento adquirido sobre sexualidade. As percepções sobre a sexualidade são infantilizadas e as famílias tem dificuldades em prover educação sexual. Conclusões: o estudo aponta a necessidade da criação de estratégias de educação em saúde sexual e reprodutiva para esta população, inclusive como forma de proteção dessas pessoas.
\end{abstract}

PALAVRAS-CHAVE: Sexualidade. Deficiência intelectual. Terapia ocupacional.

RESUMEN: La sexualidad de las personas con discapacidad intelectual sigue siendo un tabú, pero la terapia ocupacional la entiende como una etapa fundamental de la vida. Objetivo: describir la percepción de las personas con discapacidad intelectual sobre la sexualidad. Método: estudio exploratorio descriptivo, de carácter cualitativo, realizado con ocho estudiantes de una institución para personas con discapacidad, con edades comprendidas entre 13 y 42 años. Se utilizó una entrevista semiestructurada para investigar la percepción de la sexualidad y recolectar datos sociodemográficos; para la evaluación de los datos se utilizó el análisis de contenido temático-categórico. Resultados: el análisis de contenido permitió establecer dos categorías temáticas: experiencias en las relaciones afectivas; y conocimientos adquiridos sobre la sexualidad. Las percepciones sobre la sexualidad están infantilizadas y las familias tienen dificultades para brindar educación

\footnotetext{
${ }^{1}$ Universidade Federal do Triângulo Mineiro (UFTM), Uberaba - MG - Brasil. Terapeuta Ocupacional no Departamento de Terapia Ocupacional. Mestrado em Assistência ao Paciente Oncológico (UNICAMP). ORCID: http://orcid.org/0000-0002-7407-7022.E-mail: pamelaargenton@gmail.com

${ }^{2}$ Universidade Federal do Triângulo Mineiro (UFTM), Uberaba - MG - Brasil. Professora Adjunta no Departamento de Terapia Ocupacional. Doutorado em Saúde na Comunidade (USP). ORCID: http://orcid.org/0000-0001-6014-0468.E-mail: andrea.pereira@uftm.edu.br
} 
sexual. Conclusiones: el estudio señala la necesidad de crear estrategias de educación en sexualidad y salud reproductiva para esta población, incluso como una forma de proteger a estas personas.

PALABRAS CLAVE: Sexualidad. Discapacidad intelectual. Terapia ocupacional.

ABSTRACT: The sexuality of people with intellectual disabilities is still a taboo, but it is understood by occupational therapy as a fundamental stage in life. Objective: To describe the perception of people with intellectual disabilities about sexuality. Method: a descriptive exploratory study of qualitative nature was carried out with eight students - aged between 13 and 42 years, from an institution for people with disabilities. A semi-structured interview was used to investigate the perception of sexuality and collect sociodemographic data; Thematiccategorical content analysis was used for data evaluation. Results: content analysis made it possible to establish two thematic categories: experiences in affective relationships and knowledge acquired about sexuality. Perceptions about sexuality are infantilized and families find it difficult to provide sex education. Conclusions: the study points out the necessity to create strategies to better teach sexuality and reproductive health for this population, also as a way of protecting these people.

KEYWORDS: Sexuality. Intellectual disability. Occupational therapy.

\section{Introdução}

A deficiência pode fazer parte da condição humana. Alguns aspectos relacionados às pessoas com deficiência ainda são pouco discutidos, tanto no Brasil quanto no cenário internacional, como, por exemplo, o despertar da sexualidade genital, amplamente reconhecido como uma característica da adolescência humana (MAIA, 2016). O desenvolvimento da sexualidade é uma etapa fundamental do ser humano. Todas as pessoas, incluindo aquelas com deficiência, têm direito ao exercício saudável da sexualidade, que é parte integrante da personalidade de cada um. É uma necessidade básica e um aspecto do ser humano que não pode ser separado das outras dimensões da vida. Ela influencia pensamentos, sentimentos, ações, interações, tanto na saúde física como na mental (GUEX; TASCHETTO, 2014).

De modo geral, a sexualidade ainda é um tabu em nossa sociedade. Por esse motivo, lidar com a educação sexual de filhos e de alunos também pode ser difícil para muitos pais e educadores. A angústia e a dificuldade aumentam quando se trata da sexualidade de pessoas com algum tipo de deficiência, principalmente a intelectual (GUEX; TASCHETTO, 2014). Contudo, de acordo com a Declaração dos Direitos Sexuais (WORLD ASSOCIATION FOR SEXUAL HEALTH, 2014), no que se refere ao direito a igualdade e a não discriminação, 
Todos têm o direito de usufruir dos direitos sexuais [...], sem distinção de qualquer tipo, seja raça, etnia, cor, sexo, linguagem, religião, opinião política ou outra qualquer, origem social ou regional, local de residência, características, nascimento, deficiência, idade, nacionalidade, estado civil ou familiar, orientação sexual, identidade e expressão de gênero, estado de saúde, situação econômica, social ou outra qualquer.

Assim sendo, a educação sexual também deve ser para todos.

A terapia ocupacional dedica-se ao Desempenho Ocupacional e às atividades cotidianas dos indivíduos (AOTA, 2014), as quais estão dispostas em oito áreas ocupacionais dos Domínios e Processos da Terapia Ocupacional: Atividades Básicas de Vida Diária; Atividades Instrumentais de Vida Diária; Sono e Descanso; Educação; Trabalho; Brincar; Lazer e Participação Social. Essas atividades estão relacionadas às necessidades humanas de autocuidado, entretenimento e participação social, e, por serem realizadas de acordo com valores culturais, fornecem estrutura e significado à vida das pessoas.

Assim, compreendendo o exercício saudável da sexualidade como fundamental para vida do ser humano, esta pesquisa objetiva descrever a percepção de pessoas com deficiência intelectual sobre a sexualidade.

\section{Materiais e método}

Caracteriza-se por um estudo de campo, exploratório, descritivo e de natureza qualitativa. Esta pesquisa trabalha com o universo dos significados, dos motivos, das aspirações, das crenças, dos valores e das atitudes, por meio da realidade vivida e partilhada. O universo da reprodução humana é o objeto da pesquisa qualitativa que dificilmente pode ser traduzido em números e indicadores quantitativos (MINAYO, 2009).

A pesquisa foi realizada em uma instituição que tem por objetivo o tratamento, a promoção do bem-estar e o desenvolvimento da pessoa com deficiência, seja ela física ou intelectual, localizada no interior de Minas Gerais, que a época da pesquisa atendia 400 pessoas, crianças, adolescentes e adultos, diariamente. Conta com profissionais na área clínica (médico pediatra, neurologista, fisioterapeuta, psicólogo, fonoaudiólogo, nutricionista, enfermeiro, assistente social e terapeuta ocupacional) e pedagógica. A escolha desta instituição se deu em função da população atendida e por este local ser campo de atuação de estágio do Curso de Terapia Ocupacional de uma Universidade Federal, sendo esta pesquisa realizada para o trabalho de conclusão de curso de uma das autoras. 
Participaram deste trabalho oito pessoas com deficiência intelectual, com idade entre 13 e 42 anos, que tiveram o nome aqui alterado conforme escolha própria do participante para preservação de suas identidades, convidados a participar conforme os seguintes critérios de inclusão: (a) ter diagnóstico de deficiência intelectual, dado pelo profissional médico, registrado em prontuário da instituição; (b) ter condições de fala compreensível, indicado pelo profissional fonoaudiólogo do serviço; (c) ter 12 anos de idade ou mais; e (d) aceitar participar da pesquisa, por meio do termo de assentimento e ter autorização de um responsável legal por meio do Termo de Consentimento Livre e Esclarecido. Foi dado autonomia aos participantes para que escolhessem os nomes fictícios pelos quais gostariam de ser chamados, mantendo o anonimato como preconiza a Resolução 466/2012.

Para a coleta de dados foi elaborado um roteiro de entrevista, que versava sobre como a pessoa com deficiência intelectual percebe e vivencia sua sexualidade; afeto; namoro; métodos contraceptivos; como a família aborda essas questões. Foi realizado um estudo piloto, por meio do qual as questões foram adequadas para atender aos objetivos do trabalho. As entrevistas foram gravadas em mp3 e as observações registradas em diário de campo, envolvendo os aspectos do ambiente da instituição e relacionais sobre os participantes. Cada entrevista foi realizada uma única vez, com abordagem individual, conduzida pelas pesquisadoras em sala reservada na instituição, em novembro de 2018 e teve duração de aproximadamente 15 minutos. As entrevistas foram transcritas pelas pesquisadoras após seu término, com dupla verificação do conteúdo. Antes do início da entrevista realizou-se a explicação sobre a pesquisa e assinatura dos Termos de Assentimento.

A população foi composta pelo método de amostragem não probabilística intencional, submetida à disposição de cooperação por parte dos participantes e seus responsáveis. A captação ocorreu por intermédio do fonoaudiólogo, orientando quais eram os indivíduos que seriam capazes (quanto a fala) de responder as perguntas desta pesquisa. Os pais ou responsáveis pelos participantes foram abordados pelas pesquisadoras para autorizarem a participação no estudo por meio do termo de consentimento livre e esclarecido (TCLE). Nos casos de consentimento, as pesquisadoras orientaram sobre o preenchimento do TCLE e disponibilizaram este documento, assegurando uma cópia para os participantes. Após esta autorização, as pessoas com deficiência intelectual, maiores de 12 anos, que frequentavam a instituição foram convidadas a participarem da pesquisa, respondendo a entrevista e assinando o termo de assentimento. Foram esclarecidos os objetivos do estudo, assim como seus benefícios e riscos aos responsáveis e aos participantes. 
As narrativas obtidas com as entrevistas foram avaliadas por meio da análise de conteúdo temática adaptada para pesquisas qualitativas (BARDIN, 2010). Modalidade que exige, inicialmente, uma leitura compreensiva, e exaustiva, do conjunto do material selecionado. Aqui, busca-se obter uma visão de conjunto; apreender as particularidades do conjunto do material a ser analisado; elaborar pressupostos iniciais que servirão de parâmetro para a análise e a interpretação do material; escolher formas de classificação inicial; determinar os conceitos teóricos que orientarão a análise (BARDIN, 2010).

$\mathrm{Na}$ segunda etapa, realiza-se uma exploração do material. Nesta etapa procura-se distribuir trechos, frases ou fragmentos de cada texto de análise pelo esquema e classificação inicial; fazer uma leitura dialogando com as partes do texto da análise, em cada classe; identificar por meio de inferências, os núcleos de sentido apontados pelas partes dos textos em cada classe do esquema de classificação; dialogar com os núcleos de sentido com os pressupostos iniciais e, se necessário, realizar outros pressupostos. Na sequência, analisa-se os diferentes núcleos de sentido presentes nas várias classes do esquema de classificação; reagrupam-se as partes do texto por temas encontrados; elabora-se uma redação por tema. Como etapa final, constrói-se uma síntese interpretativa por meio de uma redação que possa dialogar com os dados encontrados na pesquisa, os objetivos do estudo e com o referencial teórico encontrado na literatura (BARDIN, 2010). A partir da análise do conteúdo das entrevistas foi possível estabelecer duas categorias temáticas: experiências em relacionamento afetivo; e conhecimento adquirido sobre sexualidade.

O desenvolvimento deste estudo seguiu todas as normas éticas norteadoras dos trabalhos que envolvem seres humanos, da Declaração de Helsinki (1964, última revisão em 2000), da legislação específica do Brasil e da Convenção Internacional dos Direitos Humanos, sendo aprovado pelo Comitê de Ética em Pesquisa da Universidade Federal do Triângulo Mineiro - UFTM, parecer CAAE 51665615.4.0000.5154.

\section{Resultados e discussão}

Foram selecionadas 10 pessoas que respondiam aos critérios de inclusão da pesquisa, mas participaram apenas oito porque dois usuários não se encontravam na instituição no dia em que foi agendada a coleta de dados. Foram entrevistadas quatro pessoas do sexo feminino e quatro do masculino. A idade dos entrevistados variou de 13 a 42 anos. Todos os participantes haviam sido diagnosticados com alguma deficiência intelectual pelo profissional 
médico de serviço, sendo tal informação obtida no prontuário dos usuários. A caracterização dos participantes foi apresentada na tabela 1.

Tabela 1 - Caracterização dos participantes.

\begin{tabular}{lclc}
\hline Nome & Idade & Diagnóstico & Sexo \\
\hline Talia & 28 & Síndrome de Down & $\mathrm{F}$ \\
Michael & 40 & Síndrome de Down & $\mathrm{M}$ \\
Ana Raio & 35 & Síndrome de Down & $\mathrm{F}$ \\
Giovana & 42 & ADNPM* & $\mathrm{F}$ \\
Transformes & 17 & Retardo Mental Moderado & $\mathrm{M}$ \\
Bob esponja & 13 & Retardo Mental Moderado & $\mathrm{M}$ \\
Minnie & 16 & Deficiência Cognitivo & $\mathrm{F}$ \\
Batman & 29 & ADNPM* & $\mathrm{M}$ \\
\hline
\end{tabular}

* Atraso no Desenvolvimento Neuropsicomotor

Fonte: Elaborado pelas autoras (2018)

A partir da análise das narrativas foi possível estabelecer duas categorias temáticas: experiências em relacionamento afetivo; e conhecimento adquirido sobre sexualidade.

$\mathrm{Na}$ categoria 'experiências em relacionamento afetivo' foram relatadas as vivências daqueles participantes que já tiveram algum tipo de relacionamento amoroso, como namoro ou noivado. Essa experiência foi vivida por quatro pessoas, sendo três do sexo feminino e uma do sexo masculino, que fizeram referências a dar as mãos, abraçar, beijar no rosto, beijar na boca, o desejo de ter filhos e se casar.

Giovana relatou que quando o parceiro tentava relacionar-se sexualmente, ela terminava o relacionamento: "Tenho vergonha. Nos beijávamos na boca, ele queria transar comigo e eu caí fora. Aí ele pegou minha amiga”.

Alguns entrevistados relataram que os pais acham feio seus filhos namorarem ou terem algum relacionamento afetivo, ou justificam para eles que não estão na idade adequada para namorar. Algumas famílias infantilizam seus filhos para que evitem esse tipo de relacionamento. Aqueles que nunca namoraram referiram que sabem falar sobre o assunto porque essa informação foi construída por meio de novelas, filmes e observações entre pai e mãe. Talvez o medo de se relacionar sexualmente esteja relacionado à abordagem dos pais em relação ao namoro, que muitas vezes são repressoras. Também pode ser devido à falta de 
informação e educação sobre sexualidade, pois, como muitas vezes se comportam de maneira infantilizada, seus educadores e cuidadores acreditam que não se desenvolverão sexualmente e não sentirão desejo ou atração sexual. Em concordância com Jahoda e Pownall (2014), se os pais reconhecerem que seus filhos estão se tornando mais autônomos e têm potencial para tornar-se sexualmente ativos, eles podem se sentir motivados a ajudar e a garantir que os filhos obtenham informações suficientes para permanecerem seguros.

Taila, a única entrevistada que foi noiva, relatou como foi esse relacionamento e porque acabou. Disse: "Fui noiva. Dava as mãos, abraçava, beijava na boca. [...] Eu morava em São Paulo e ele na Bahia. Nunca esqueci ele”.

Para Bob Esponja namorar é dar beijo no rosto, contudo sua mãe diz que não pode fazer esse tipo de carinho em outras pessoas e que namorar é feio. O participante se mostra confuso em responder se namorar é feio ou não, e relata que a irmã dele deveria acabar de namorar para ele começar: "Já [namorei]. Minha mãe não deixa dar beijo no rosto, minha mãe fala que não pode. Tem que esperar a Carol namorar e depois eu posso".

A negligência desse assunto que permeia a atualidade da nossa sociedade, na qual namoro, casamento, atividades sexuais são normais para pessoas que possuem corpos perfeitos ou não tem nenhuma deficiência intelectual, gera uma inquietação progressiva para aqueles que tem alguma deficiência, pois o acesso à televisão e às redes sociais permite o contato com o tema, proporcionando assim a curiosidade, mas não o exercício saudável da sexualidade. Ou seja, é razoável sugerir que não é apenas a falta de conhecimento, mas também o desconforto dos jovens com a sua sexualidade em desenvolvimento pode estar ligado à sua confusão e vergonha sobre sentimentos sexuais e ansiedade sobre a expressão sexual. Portanto, a incapacidade de desenvolver uma visão mais equilibrada ou positiva de sua própria sexualidade pode reduzir o senso de gerência e controle dos jovens, tornando-os mais relutantes em buscar as informações de que necessitam ou criar a confiança para expressar seus próprios desejos de relacionamentos íntimos (JAHODA; POWNALL, 2014).

Observa-se que pela falta de uma educação sexual e de informações sobre relacionamentos afetivos os participantes não exercem de maneira saudável a sexualidade, uma ocupação humana essencial. Essa educação poderia ser utilizada como forma de intervenção tanto para os participantes, como para pais e educadores, oferecendo orientações adequadas para as pessoas com deficiência intelectual para que possam exercer de forma saudável essa atividade de vida diária, que não se limita ao ato sexual, mas envolve os afetos e relações, naturais para vida humana. 
Na categoria 'conhecimento adquirido sobre sexualidade' foi abordada como os pais orientam seus filhos com deficiência intelectual sobre a sexualidade ou outras formas pelas quais adquirem conhecimento sobre o tema. Foi perguntado aos participantes se os pais falavam sobre namoro e sexualidade, se eles sabiam o que é namoro, como que as pessoas namoram, foi notável a existência muitas dúvidas. Os participantes que nunca tiveram nenhum relacionamento afetivo referem que tem a ideia de que é um relacionamento entre duas pessoas, no qual elas podem ter uma relação amorosa com beijos no rosto, abraço e andar de mãos dadas.

Percebe-se que os familiares infantilizam esses indivíduos pelo fato de serem pessoas com deficiência intelectual. Muitos participantes relataram que não sabiam o que era namoro, não sabiam o que faziam os namorados, que se sentiam errados em conversar sobre o assunto de relacionamentos afetuosos. Algumas famílias diziam ser incorreto dar beijo no rosto, beijo na boca, andar de mãos dadas, abraçar e ter relacionamentos afetuosos, como a de Batman: "Nunca namorei. Não sei o que é namorar. Minha família fala que é feio. [você acha feio namorar?] Não. [você já viu em novela, filme?] Já, é dar beijo na boca, dar as mãos, abraçar”.

Muitos fatores podem influenciar os indivíduos em relação à sua sexualidade, por exemplo, a sociedade, valores familiares, crenças religiosas e deficiências intelectuais (MAIA, 2016). Essa construção e compreensão do assunto namorar, está interligada na maneira como a família aborda esse tema. Porém, alguns entrevistados demostram conhecimento sobre o tema e, mesmo a família dizendo que namorar é errado, eles discordam da opinião da família, como Minnie, que namorou com o consentimento da mãe, mas escondido do pai:

Já namorei. Foi bom. A gente fazia um bocado de coisas. Ele é da igreja da minha tia, mas a igreja não deixa. A gente dava beijo só no rosto, não dava mão e nem abraçava. [Sua família sabe?] Só minha mãe, ela achou bom, somos amigas. Meu pai não pode saber que ele bate no couro (Minnie).

Observa-se o autoritarismo e o tabu que permeia esse assunto. Os pais e os educadores muitas vezes negam a existência da sexualidade e preferem encarar o filho e o aluno com deficiência como assexuado. As pessoas com deficiência não precisam de piedade, mas de compreensão quanto à sua condição e, principalmente, de esclarecimento convincente para adequar seu comportamento, tornando-o menos excludente. Uma das principais fontes de preconceitos é a desinformação existente acerca das potencialidades, desejos e dificuldades, deste grupo da população (LITTIG et al., 2012). Quando o tema passa a ser sexualidade da pessoa com deficiência, o preconceito e a discriminação são intensificados e causam 
controvérsias quanto às diferentes formas de abordá-lo, tanto com os próprios adolescentes, quanto com suas famílias e na escola. No entanto, pais e educadores devem educá-los com franqueza no aspecto da sexualidade para que eles percebam que possuem papel sexual definido e com necessidades iguais às de qualquer ser humano (MAIA et al., 2015).

Quando perguntado, para os participantes que nunca tiveram um relacionamento, se a família conversa sobre namoro, relacionamento e sexo, a maioria relatou que não conversam e também não deixam eles namorarem, por vários motivos como os citados: que é feio, que ainda não têm idade, ou simplesmente porque não pode. $\mathrm{O}$ único que disse que a família conversa foi Batman, mas que a mãe só diz que é feio e que não pode, não há uma explicação sobre essas questões.

Toda família necessita de tempo e um espaço para explorar seus medos e a ansiedade relacionados à sexualidade de seus filhos adolescentes e precisam de orientação específica educá-los para cada fase da vida. A sexualidade faz parte da vida e do processo de desenvolvimento e educação do ser humano e, como tal, deve ser abordada também com as pessoas com deficiência, numa construção gradativa do ser humano, favorecendo uma personalidade psicologicamente sadia e socialmente adequada (CABRAL; MOURA; MOURA, 2016).

A relação entre pais e filhos com deficiência intelectual evidencia uma caracterização infantilizada nesse contato. Os pais educam seus filhos pensando em suas dificuldades e não nas habilidades que podem ser desenvolvidas e/ou aprimoradas durante o desenvolvimento. Assim, os filhos apresentam dificuldades em potencializar uma opinião própria sobre a sexualidade, sendo essa algumas vezes negligenciada pela família (LITTIG et al., 2012).

A educação sexual se dispõe do conhecimento e informações que os pais, cuidadores e outros profissionais disponibilizam e compartilham sobre a sexualidade desses indivíduos, isso permite que eles tenham comportamentos adequados no tocante às vivencias e mudanças de comportamentos perante sua maturação sexual. Ou seja, é uma tarefa que cabe à família, à escola ou aos profissionais envolvidos nos cuidados de crianças e adolescentes. Ela deve começar no contexto familiar e ir se ampliando ao longo da vida de cada ser humano. De maneira mais sistemática deve ocorrer por meio de orientadores capacitados, tendo por objeto: fazer com que a pessoa com deficiência intelectual compreenda o que está acontecendo com o próprio corpo; prevenir abusos sexuais, divulgar os principais códigos que regem o comportamento sexual, oferecer subsídios à família e à instituição para equacionar o relacionamento entre elas e a pessoa com deficiência mental, no tocante às condutas sociais (CABRAL; MOURA; MOURA, 2016). 


\section{Considerações finais}

O estudo aponta que os participantes dessa pesquisa, pessoas com deficiência intelectual, pouco sabem sobre sexualidade e relacionamentos afetivos. Ainda, que suas percepções sejam formadas a partir de observações do cotidiano ou programas de televisão e rede sociais por onde apreendem o que acreditam ser o exercício da sexualidade, não tendo a educação sexual por parte de familiares, nem sistematizada pelas instituições em suas vidas.

Inquieta-se com a escassez de publicações acerca deste tema, considerando que pesquisas como essas devam ser publicadas, já que atividade sexual é considerada uma atividade de vida diária e uma ocupação da qual a terapia ocupacional se empenha.

De maneira geral, as famílias e os educadores necessitam de um espaço que oportunize um momento para fazer orientação sobre a sexualidade, mas também necessitam de apoio e referência sobre como fazê-la. Em vista desses apontamentos, considera-se que a terapia ocupacional pode implementar ações para contribuir não só para as pessoas com deficiência intelectual, como para seus pais e educadores, no sentido de promover orientações para essas pessoas, além de possibilitar mudanças nas representações sociais acerca da sexualidade das pessoas com deficiência intelectual, contribuindo assim, para que se tenha uma maior compreensão do relacionamento afetivo desse grupo e o direito a prática e expressão saudável da sexualidade.

\section{REFERÊNCIAS}

AMERICAN OCCUPATIONAL THERAPY ASSOCIATION, AOTA. Estrutura da prática da Terapia Ocupacional: domínio \& processo. Revista de Terapia Ocupacional

Universidade de São Paulo, Brasil, v. 26, n. esp., p. 1-49, abr. 2015.

BARDIN, L. Análise de conteúdo. 4. ed. Lisboa: Edições 70; 2010. 229 p.

CABRAL, P. P.; MOURA, C. B.; MOURA, C. E. Concepções de Sexo e Sexualidade entre Pais e Adolescentes. Pleiade, v.10, n. 20, p. 61-66, jul./dez. 2016. Disponível em: https://pleiade.uniamerica.br/index.php/pleiade/article/view/311. Acesso em: 8 maio 2020.

GUEX, U. T. S.; TASCHETTO, O. M. Sexualidade para todos, sem exclusão. Programa de Desenvolvimento Educacional (PDE), Paraná, 2014. p. 1-13. Disponível em: 
http://www.diaadiaeducacao.pr.gov.br/portals/pde/arquivos/1894-8.pdf. Acesso em: 15 maio 2020.

JAHODA, A.; POWNALL, J. Sexual understanding, sources of information and social networks; the reports of young people with intellectual disabilities and their non-disabled peers. Journal of Intellectual Disability Research: JIDR, Nova Jersey, v. 58, n. 5, p. 430441, maio 2014. Disponível em: https://eric.ed.gov/?id=EJ1022901. Acesso em: 15 maio 2020.

LITTIG, P. M. C. B. et al. Sexualidade na deficiência intelectual: uma análise das percepções de mães de adolescentes especiais. Rev. bras. educ. espec., Marília, v. 18, n. 3, p. 469-486, set. 2012. Disponível em: http://www.scielo.br/scielo.php?script=sci_arttext\&pid=S141365382012000300008\&lng=en\&nrm=iso. Acesso em: 15 maio 2020.

MAIA, A. C. B. et al. Opinião de professores sobre a sexualidade e a educação sexual de alunos com deficiência intelectual. Estud. psicol., Campinas, v. 32, n. 3, p. 427-435, set. 2015. Disponível em: http://www.scielo.br/scielo.php?script=sci_arttext\&pid=S0103166X2015000300427\&lng=en\&nrm=iso. Acesso em: 15 maio 2020.

MINAYO, M. C. S. (Org.). Pesquisa social: teoria, método e criatividade. 29. ed. Petrópolis, RJ: Vozes, 2019. 108 p.

WORLD ASSOCIATION FOR SEXUAL HEALTH. The Declaration of Sexual Rights. Spain, 2014. Disponível em: http://www.worldsexology.org/wpcontent/uploads/2013/08/declaration_of_sexual_rights_sep03_2014.pdf. Acesso em: 8 maio 2020.

MAIA, A. C. B. Vivência da sexualidade a partir do relato de pessoas com deficiência intelectual. Psicologia em Estudo, v. 21, n. 1, p. 77-88, 12 jul. 2016. Disponível em: http://periodicos.uem.br/ojs/index.php/PsicolEstud/article/view/29480. Acesso em: 8 maio 2020.

\section{Como referenciar este artigo}

PUGA, P. C. A.; RUZZI-PEREIRA, A. A percepção sobre a sexualidade de pessoas com deficiência intelectual. Temas em Educ. e Saúde, Araraquara, v. 16, n. 2, p. 542-552, jul./dez. $2020 . \quad$ e-ISSN 2526-3471. ISSN $1517-7947 . \quad$ DOI: https://doi.org/10.26673/tes.v16i2.13709

Submetido em: $21 / 03 / 2020$

Revisões requeridas: $30 / 05 / 2020$

Aprovado em: 19/07/2020

Publicado em: 27/08/2020 